\title{
PROFESSORAS-EM-CONSTRUÇÃO: REFLEXÕES SOBRE DIÁRIOS DE APRENDIZAGEM E FORMAÇÃO DOCENTE
}

\author{
Carla L. ReichmanN
}

Universidade Federal da Paraíba

Resumo: Este artigo objetiva lançar um olhar sobre narrativas docentes produzida por duas professoras de língua inglesa/ mestrandas que cursaram a disciplina Fundamentos de Lingüística Aplicada (ministrada pela autora em 2006/1). Simultaneamente constituindo histórias singulares de aprendizagem docente e construindo conjuntamente um mosaico de 'paisagens de saberes profissionais' (CONNELLY e CLANDININ, 1999), as narrativas focalizam diários de aprendizagem produzidos ao longo dessa disciplina, voltada à formação, pesquisa e identidade docente (FAIRCLOUGH, 1992; MOITA LOPES, 1996, 2004; FREEMAN, 1996; LUDKE, 2001; CELANI e MAGALHÃES, 2002; BURTON, 2005; GIMENEZ, 2005; KLEIMAN e MATÊNCIO, 2005 entre outros). Esta análise de cunho interpretativo discute os (re) posicionamentos mais salientes nas narrativas. Em suma, serão discutidas as implicações deste estudo em andamento em termos de formação e identidade docente.

Palavras-chave: formação de professores, diários reflexivos, narrativas docentes

Abstract: This article aims at discussing teacher narratives produced by two English as a Foreign Language teachers/ graduate students who attended a course on Foundations of Applied Linguistics (delivered by the author in 2006/1). Simultaneously constituting unique teacher learning stories and jointly constructing a mosaic of professional knowledge landscapes' (CONNELLY \& CLANDININ, 1999), the narratives focus on learning journals written along the course, anchored on teacher identity, research and development (FAIRCLOUGH, 1992; MOITA LOPES, 1996, 2004; FREEMAN, 1996; LUDKE, 2001; CELANI \& MAGALHÃES, 2002; BURTON, 2005; GIMENEZ, 2005; KLEIMAN e MATÊNCIO, 2005 amongst 
110 Reichmann - Professoras-em-construção: reflexōes sobre diários...

others). This interpretative analysis highlights the most salient (re)positionings in the narratives. Implications will be discussed in terms of teacher identity and development.

Key words: teacher development, reflective journals, teacher narratives.

\section{Introdução}

... as identidades sociais e profissionais típicas não são nem expressões psicológicas de personalidade individuais nem produtos de estruturas ou de políticas econômicas impostas de cima, mas sim construções sociais que implicam a interação entre trajetórias individuais e sistemas de emprego, de trabalho $e$ de formação. Resultados sempre precários ainda que muito fecundos de processos de socialização, essas identidades constituem formas sociais de construção de individualidades a cada geração, em cada sociedade. (DUBAR, 2005:33)

Partindo-se das premissas que (i) a linguagem constitui e é constituída por processos sociais, construindo relações e identidades sociais e sistemas de saberes e crenças (FAIRCLOUGH, 1992,) ${ }^{1}$; (ii) aprender a construir textos e familiaridade com gêneros textuais requer prática social (HASAN, 1989); (iii) saberes são construídos em contextos sociais, quando pessoas interagem (VYGOTSKY, 1978); e (iv) a escrita reflexiva é uma ação profissional (BURTON, 2005), este artigo tem como objetivo lançar um olhar sobre narrativas docentes produzidas por duas professoras de língua inglesa atuando na rede pública -- uma engajada no ensino fundamental, outra no ensino superior -- ambas cursando a disciplina Fundamentos de Lingüística Aplicada (ministrada pela autora no primeiro semestre de 2006). Simultaneamente constituindo histórias singulares de aprendizagem docente e construindo conjuntamente um mosaico de 'paisagens de saberes profissionais' (CONNELLY e CLANDININ, 1999), essas narrativas focalizam em especial os diários de aprendizagem produzidos ao longo da disciplina, voltada à formação, pesquisa $\mathrm{e}$ identidade docente (MOITA LOPES, 1996, 2004; FREEMAN, 1996; McDONOUGH e McDONOUGH, 1997; LUDKE, 2001; CELANI e MAGALHÃES, 2002; BURTON, 2005; GIMENEZ, 2005; KLEIMAN e MATÊNCIO, 2005, entre outros). Alicerçadas em um gênero

'As traduções de citações neste artigo são de responsabilidade da autora. 
específico de escrita reflexiva -- diários de aprendizagem (gênero textual na qual a própria trajetória profissional da autora está ancorada) -- as narrativas docentes serão contrastadas em termos dos (re)posicionamentos construídos ao longo dos textos.

De acordo com Johnson (2006), a recente virada sócio-cultural nas ciências humanas teve um impacto significativo no modo como a área de formação docente entende a maneira pela qual professores de língua estrangeira aprendem a profissão. Johnson (2006:235) aponta quatro desafios inter-relacionados advindos dessa virada: (i) teoria/prática versus práxis; (ii) a legitimação dos saberes docentes; (iii) a reconfiguração das fronteiras de formação profissional e (iv) a formação localizada'de professores de língua estrangeira. Esclarecendo o último ponto,

a formação localizada' de professores de língua estrangeira reconhece porque professores de língua estrangeira fazem o que fazem, imersos em contextos sociais, históricos e culturais onde seu trabalho está inserido e a partir daí se empenha em co-construir com os professores respostas localmente apropriadas às suas necessidades de formação docente. (JOHNSON, 2006:246).

A lingüista acrescenta que é crucial integrar em ações de formação docente as experiências prévias dos professores, suas interpretações em relação às atividades nas quais se engajam, como também o contexto de atuação profissional. Como bem coloca Signorini (2006:201),

... quando se pretende de alguma forma intervir nessas práticas [docentes], como no caso de cursos de formação, é preciso estar atento a essas configurações locais, específicas e fluídas de ordem institucional. E são vetores fundamentais dessas configurações locais as assimetrias de poder e saber que se constroem e se transformam nas interações sociais, tanto entre professores e agentes da burocracia estatal quanto entre professores e seus aprendizes...

Alinhando-se aos pontos acima mencionados, Gimenez (2005:199) sinaliza alguns desafios em relação à Lingüística Aplicada e formação docente no cenário brasileiro, tais como a definição da base de conhecimento profissional e a identidade profissional dos formadores, entre outros. É relevante sublinhar, conforme colocado na epígrafe, que trajetórias individuais e sistemas de emprego, trabalho e formação produzem uma complexa trama constituindo 
112 Reichmann - Professoras-em-construção: reflexões sobre diários...

identidades sociais e profissionais. Seguindo nesta direção, este artigo dá visibilidade a um momento na trajetória de uma formadora, momento em que, na tentativa de promover um trabalho coerente com o que é colocado acima, sua história perpassa outras histórias profissionais. Dito de outra forma, momento em que uma formadora lança um desafio e duas professoras de inglês mergulham em diários de aprendizagem (também denominados diários reflexivos ou diários docentes) e depois compartilham esse mergulho em seus relatos finais na disciplina ${ }^{2}$.

As seções a seguir abordam diários de aprendizagem, histórias da formadora, histórias das professoras e uma análise de cunho interpretativo. Na conclusão serão tecidas algumas considerações sublinhando o impacto vital da documentação da prática profissional através de diários e relatos reflexivos em contextos de formação docente.

\section{O diário de aprendizagem}

Inicialmente, apresentou uma breve explicação sobre diários de aprendizagem (ou diários reflexivos) e narrativas docentes em contextos universitários de formação continuada, o foco deste trabalho. O diário de aprendizagem, como gênero acadêmico, é essencialmente um espaço narrativo pessoal, protegido, onde o professor/aprendiz/autor pode colocar suas dúvidas, anseios, percepções, questões, críticas, conflitos - enfim, documentar suas tensões, reflexões e (re)elaborar crenças e práticas. Colocado na posição de autor, o professor/aprendiz constrói um espaço narrativo singular, textualizando um diálogo interior. Se esse texto é compartilhado ou não com o resto do grupo, por exemplo, de que maneira, depende de uma negociação coletiva dos participantes. Em termos de aprendizagem, conscientização e transformação, o particularmente interessante de um diário é seu aspecto longitudinal. A escrita diarista permite um valioso distanciamento crítico, possibilitando a observação e reflexão - esta afirmação é uma constante entre professores-autores. $O$ 'insight' possibilitado por releituras é um aspecto fascinante, tocadas pelo posicionamento sempre em fluxo do leitor/autor. No caso dos diários da disciplina em questão, produzidos por professoras em

${ }^{2}$ Cabe mencionar a colocação de Signorini (2006:56) “[d]o relato do professor como dado de pesquisa". 
atuação e formação ao longo de um semestre acadêmico, os textos não foram compartilhados coletivamente; esporadicamente foram realizadas discussões sobre desafios, benefícios e 'insights' relativos à produção diarista em curso.

Ao criar seu próprio objeto de estudo, a documentação de discursos e construções identitárias de professores constitui um campo riquíssimo para pesquisa docente, possibilitando ao próprio professor retextualizar sua prática, utilizando sua própria sala de aula como espaço de formação. Vários pesquisadores/formadores, com abordagens diversas, têm realizado estudos sobre diários e narrativas de aprendizagem em contextos de formação inicial e continuada de professores de língua estrangeira, tais como Bailey (1990), Connelly e Clandinin (1999), Liberali (1999), Burton e Carroll (2001), Johnson e Golombek (2001), Mello (2005) e Burton, Quirke e Reichmann (em preparação), entre outros. Narrativas de aprendizagem, na forma de relatos e diários reflexivos, possibilitam justamente um retextualizar da prática, de histórias e trajetórias. Alinhando-se a Signorini (2006, contra-capa), os diários e relatos reflexivos são aqui considerados

como gêneros discursivos que assumem uma função catalisadora do processo de ensino em curso, ou seja, que favorecem o desencadeamento e a potencialização de ações e atitudes consideradas mais produtivas para o processo de formação, tanto do professor quanto de seus aprendizes...

Dessa forma, considerando o diário de aprendizagem como um gênero catalisador, a autora tem utilizado diários de várias formas, dependendo do contexto. Por exemplo, aluno-aluno, aluno-professor, ou individualmente. Nessa disciplina a opção foi por diários de aprendizagem individuais, onde os participantes documentaram seu processo de aprendizagem, visando criar a base para a produção de um relato reflexivo no final do semestre. Em relação a relatos reflexivos, Signorini $\left(2006\right.$, p.55) ${ }^{3}$ afirma que o gênero encapsula duas funções vitais:

A primeira dessasfunçõeséa de darvoz aoprofessor enquanto profissional. Através da elaboração do 'relato reflexivo', são desencadeados processos de articulação e legitimação de

${ }^{3}$ Embora se referindo a relatos reflexivos autobiográicos de professores de lingua materna, 0 que afirma se aplica aos relatos em questão. 
114 Reichmann - Professoras-em-construção: reflexōes sobre diários...

posições, papéis e identidades auto-referenciadas, ou seja, construídas pelo narrador/autor para si mesmo. A segunda função é a de através da interlocução mediada pela escrita, criar mecanismos e espaços de reflexão sobre teorias e práticas que constituem os modos individuais e coletivos de compreensão e de produção /reprodução desse campo de trabalho...

Enfim, ao engajar-se na produção diarista, o profissional de linguagem se constrói discursivamente, assumindo o duplo papel de observador e observado, como no quadro "Las Meninas" ${ }^{4}$ de Velázquez (1656), onde o pintor se auto-representa, incluindo-se na narrativa visual, dando visibilidade ao autor. Nos diários e relatos reflexivos discutidos neste trabalho, são reconstruídas histórias e trajetórias profissionais - ressignificando a práxis, os fazeres e as identidades profissionais, como veremos adiante.

Alinhando-se ao construto elaborado por Smyth (1989, 1992), sobre formas de ação no processo reflexivo, buscaremos nos textos das professoras algumas reconstruções emergentes. Às vezes não apresentando separações nítidas e se fundindo, essas formas de ação reflexiva são descrever, informar, confrontar e reconstruir. Conforme aponta Romero (1998:57), essas formas "ajudariam o professor a imergir no processo reflexivo". De uma forma sucinta, as perguntas que resumiriam essas ações, seriam respectivamente, $O$ que faço? Qual o significado das minhas ações? Como me tornei assim? Como fazer diferente? Não pretendendo analisar detalhadamente as formas de ação nas narrativas docentes, mas sim ao focalizar na última pergunta, ou seja, como fazer diferente, será verificado se há reconstruções e como se alinham ao reposicionamento identitário.

\section{2. (Con)textos de uma formadora}

Norteada pela própria trajetória acadêmica e profissional, a autora assume como formadora a postura de professora-pesquisadora, ou seja, os posicionamentos de atora/analista freqüentemente se fundem (ver REICHMANN, 1992, 2001). No mestrado, a autora vivenciou um intenso processo de letramento e formação docente ancorado na produção textual através de autobiografias,

${ }^{4}$ Ao se digitar 'Las meninas, Velazquez' na ferramenta de busca 'Google', aparecem várias opções de visualização. 
rememorações, diários e relatos reflexivos, diários dialogados e gravações em vídeo -- enfim, um processo de ensino-aprendizagem voltado para a documentação e interpretação da prática através de narrativas de aprendizagem docente. Possibilitou-se a ressignificação de histórias de vida e histórias profissionais. Entre outros processos e outras práticas que facilitaram o empoderamento docente durante seu mestrado, vale mencionar a pesquisa-ação (KEMMIS e McTAGGART, 1982), aprendizagem docente (FREEMAN, 1989), reflexão crítica (BARTLETT, 1990; ELBAZ, 1988, 1991; FREIRE, 1970; ZEICHNER, 1987), reflexão-na/sobre-a-ação (SCHÖN, 1983, 1987). Como desdobramento, em termos acadêmicos, no doutorado a autora produziu um diário dialogado, analisado à luz da lingüística sistêmico-funcional (HALLIDAY, 1994), sendo que a co-autoria do diário com outra professora foi claramente uma experiência catalisadora, em termos de reposicionamentos como aprendiz, professora, pesquisadora e formadora.

Como decorrência desse percurso, foi criado o grupo de pesquisa no $\mathrm{CNPq}$ Retextualizando práticas, histórias e trajetórias de formadores e professores de $L E$, sublinhando o impacto vital da prática escrita, da mediação (VYGOTSKY, 1987) e de comunidades de prática (LAVE e WENGER, 1991) em contextos de formação de professores de língua estrangeira. A disciplina de Fundamentos de Lingüística Aplicada (doravante FLA) e as narrativas das duas professoras são facetas desse projeto, criando interfaces com outros textos em andamento ${ }^{5}$.

A seguir, lançarei um olhar sobre alguns fragmentos das narrativas das duas professoras, nos espaços narrativos onde retratam a si mesmas, suas práticas e contextos profissionais. Na seção seguinte será apresentada uma visão panorâmica dos textos, como também uma leitura dos fragmentos selecionados, que retratam diálogos interiores, diálogos entre si e diálogos com a própria formadora (autora deste artigo).

\section{3. (Con)textos de duas professoras}

Como mencionado acima, as narrativas docentes foram produzidas como trabalho/reflexão final na disciplina de FLA realizada ao longo do primeiro semestre de 2006, em uma pósgraduação em Lingüística. $\mathrm{O}$ grupo eclético e dinâmico de 31

sPor exemplo, www.professores-em-construcao.org 
116 Reichmann - Professoras-em-construção: reflexões sobre diários...

aprendizes incluiu fonoaudiólogas, professores de português, inglês, francês e espanhol, todos unidos pelo interesse comum em Lingüística Aplicada. Esta análise recai sobre o grupo de professores de língua inglesa, em especial sobre duas professoras, Ana e Maria ${ }^{6}$ (nomes fictícios) cujo engajamento com o diário é evidente ao longo da reflexão final e esta a razão principal que levou a autora a examinar seus textos, uma vez que a proposta da disciplina englobava principalmente a produção diarista.

Inicialmente, uma visão panorâmica dos textos de Ana e Maria revela que os principais temas discutidos são questões e tensões referentes às leituras, à escritura do diário e à atuação em suas respectivas salas-de-aula. Ou seja, retratam posicionamentos como professora-leitora, professora-autora e professora-em-ação. Visando investigar como as professoras representam sua vivência profissional/seu mundo de trabalho, esta análise focaliza a categoria professora-em-ação inscrita nas reflexões finais de Ana e Maria. Em outras palavras, neste recorte foram selecionados os fragmentos onde se referem a si mesmas, a outros professores no seu contexto profissional, ou a professores em geral. Foram verificados, por exemplo, trechos onde o ator social está representado na primeira pessoa do singular ou plural, eu e nós, como também representado por professores e professores de inglês na escola pública. Também ocorrem casos onde o ator social é agente de letramento, professormáquina e professor-diretor-de-peça-teatral, como veremos adiante.

No texto de Ana, professora no ensino fundamental, é saliente a questão do professor como agente de letramento (KLEIMAN e MATÊNCIO, 2005). Escreve como vê os professores no seu contexto e descreve sua própria atuação em sala de aula. Coloca que procurou a pós-graduação para entender por que a gramática é ensinada de uma forma tão tradicional na escola, e ao concluir seu relato, coloca que compreendeu o motivo pelo qual o professor ensina a gramática do modo que ensina - por não ser um agente de letramento. Como será visto adiante, seu texto apresenta uma reconstrução, quando se interroga (indiretamente) sobre a prática docente de uma forma ampla.

Já no texto de Maria, professora universitária, é saliente a questão do professor-pesquisador, tema trabalhado nos textos de

\footnotetext{
6 Agradecimentoa especiais às dedicadas professoras Ana e Maria, que generosamente compartilharam suas narrativas.
} 
Ludke (2001) e Freeman (1996). Na sua narrativa vemos descrições e reconstruções referentes a uma atividade que realizou com seus alunos, baseada na sua prática diarista em curso: reflete sobre 0 que funcionou, o que faria diferentemente e o que pretende fazer futuramente.

Em ambos os textos, é visivel a maneira semelhante como é retratada a formação de professores, evidenciando o descompasso entre a formação do professor de língua inglesa e o mundo do trabalho. As interpretações das professoras mandam um recado claro aos formadores -- as histórias vividas na universidade deixam a desejar, como podemos ver nos seguintes fragmentos (grifos meus):

\section{Fragmento (1)}

Por que não estimular alunos de escolas públicas, nas aulas de língua estrangeira, a identificar suas dificuldades, pontos fortes e despertar a auto-estima muitas vezes adormecida? Talvez alguém precise antes fazer o mesmo com os professores. Isto pode ser feito través de diálogos, de reflexões, troca de experiências, interação entre professor-aluno, alunoaluno, professor-professor. (Ana)

Nesse comentário, aludindo-se a uma interação mais significativa entre educadores e educandos, a professora entrevê a possibilidade de um diálogo mais estimulante com alunos, para assim 'acordálos'. E segue colocando a necessidade dos próprios professores vivenciarem isto, uma vez que percebe que esta prática/interação não faz parte de suas experiências prévias de formação. De uma forma contundente, coloca que alguém precisa antes fazer o mesmo com os professores. 'Alguém' - pronome indefinido para os formadores, potenciais interlocutores a quem o apelo da professora parece se dirigir. Curiosamente, de certa forma dialogando com o texto de Ana, Maria comenta o seguinte sobre seu contexto universitário, questionando e ressignificando a própria prática:

\section{Fragmento (2)}

Pergunto-me, é possível instituir a prática da pesquisa docente pelo próprio professor em sala de aula em nosso contexto? $\mathrm{O}$ que me chamou atenção, após estudar esse texto, juntamente com o de Ludke foi que a pesquisa em sala de aula feita pelo próprio professor não tem sido uma prática muito comum na 
118 Reichmann - Professoras-em-construção: reflexōes sobre diários...

universidade, tampouco nas escolas públicas ou privadas de ensino fundamental e médio Apesar de a sala de aula ser um verdadeiro laboratório, o contexto ideal para se desenvolver estudos e pesquisas sob os mais diversos enfoques. Este evento está registrado no meu diário como um fato que considero lamentável, pela contribuição que tal pesquisa traria aos alunos em processo de formação para o magistério, na área de LE. Acho que gostaria de tentar me envolver num projeto dessa natureza. (Maria)

Nesse fragmento, onde é narrado o que não tem acontecido na formação inicial, vemos justamente 'alguém' pensando em fazer algum projeto com futuros professores. Outro ponto que vale ressaltar é que no texto acima, de Maria, vê-se que a pesquisa em sala de aula não tem sido uma prática muito comum na universidade, tampouco nas escolas; no fragmento de Ana, a seguir, igualmente salta à vista o que não acontece -- a seqüência de declarativas negativas compõe um quadro estarrecedor, onde o professor é uma figura que não olha, não faz, não conhece, não consegue (grifos meus):

\section{Fragmento (3)}

Sinto que professores de inglês das escolas municipais em que ensino, muitas vezes, não estão habilitados para lecionar a disciplina. Não conhecem técnicas e metodologias adequadas c não têm tempo ou pré-disposição para trocar experiências com colegas. Neste último também me incluo. Não que a culpa seja exclusivamente nossa. Muitos de nós terminamos a graduação sem passar por nenhuma prática reflexiva sobre o nosso papel na instituição que estudamos, sem a prática de ensino em escolas, mas apenas com a "prática" da disciplina Prática de Ensino, a qual deixa a desejar. Os professores que estão em sala de aula não conseguem se aperfeiçoar. Precisam trabalhar dois ou três turnos para manter a família. A única identidade que possuem é a do professor máquina: diz "bom dia" sem olhar nos olhos dos alunos; faz a chamada de freqüência escolar pelo número da caderneta, sem olhar no rosto dos alunos; pede para um aluno qualquer devolver trabalhos e avaliações, sem olhar novamente para os alunos; olha ansioso para o relógio, e ao toque da campainha, sai de sala com um "tchau" sem olhar para trás. É assim que muitos constroem suas identidades profissionais em escolas públicas. (Ana) 
Enquanto que a pintura "Las Meninas" serve como metáfora para a autoria e pesquisa docente, aqui o que vem à mente, como representação do professor, é a triste figura do personagem Carlitos no filme "Tempos Modernos", na conhecida cena onde fica preso à engrenagem de uma máquina na fábrica onde trabalha -- como o professor-máquina retratado acima, construído como vítima, à mercê do sistema, um profissional que não é, não faz e não se assume. Se por um lado no texto de Ana vemos a construção desse professormáquina - que precisa trabalhar dois ou três turnos para manter a família, nos remetendo à colocação de Signorini (2006:69) sobre a crescente proletarização da profissão no Brasil - por outro lado, na outra ponta do contínuo, em contraposição ao professor-máquina surge no texto de Ana a figura do professor-diretor-de-peça-teatral, como vemos abaixo:

\section{Fragmento (4)}

Ser um agente de letramento é ter conhecimentos dos meios, fraquezas e forças dos membros do grupo e de suas práticas locais. É ser mobilizador de seus saberes e experiências. O professor aqui pode ser comparado a um diretor de peça teatral, fazendo com que cada ator participe de uma cena segundo suas capacidades, descobrindo talentos, fazendo com que todos atuem em seu papel de acordo com suas potencialidades. (Ana)

Após refletir sobre o professor como agente de letramento, Ana descreve sua atuação, respondendo à seguinte questão que se coloca:

\section{Fragmento (5)}

Como professores de língua estrangeira em escola pública podem ser agentes de letramento? Refletindo sobre minha prática em sala de aula de língua inglesa, percebi que posso me considerar, em algumas aulas, um agente de letramento. Eis as razões: uso, preferivelmente, fotocópias de diferentes tipos de textos; anúncios de jornal, cartas, receitas, cardápios, músicas, diálogos, quadro de feriados, gravuras de cidades, cartões postais; estimulo o aluno a levantar hipóteses sobre o assunto dos textos através de conhecimento prévio do tema, de seu conhecimento de mundo, de palavras parecidas com português, de vocabulário conhecido, de leitura das 
120 Reichmann - Professoras-em-construção: reflexōes sobre diários...

questões de compreensão; explico a gramática a partir do texto trabalhado com exemplos do próprio texto; mostro sua função e uso naquela situação específica; seleciono exercícios que estimulem o raciocínio, que façam o aluno ler o texto ou enunciado, pensar, procurar, perguntar a outras pessoas, tais como: caça-palavras, palavras cruzadas, jogo da forca, preenchimento de formulário com dados pessoais, comparações entre o conhecimento novo e o que os alunos já sabiam antes, promovo produção escrita na língua alvo através de mini-diálogos, pequenas cartas direcionadas, etc. (Ana).

Nesse trecho, a professora coloca que algumas vezes é agente de letramento. Há uma descrição do que faz em aula: uso, estimulo, explico, mostro, seleciono, promovo - assim Ana vai retratando sua atuação. Porém não surgem, por exemplo, ações relacionadas à questão lançada pela própria professora no Fragmento 1, quando indiretamente propõe uma reconstrução com sua pergunta, Por que não estimular alunos de escolas públicas, nas aulas de língua estrangeira, a identificar suas dificuldades, pontos fortes e despertar a auto-estima muitas vezes adormecida? E embora não ocorra uma indicação quanto a um reposicionamento profissional na própria atuação, há um insight referindo-se aos professores de inglês em seu contexto profissional:

\section{Fragmento (6)}

Por fim, mesmo não encontrando neste curso específicas sugestões, atividades comunicativas, estratégias de interação entre a gramática da língua materna e a gramática de uma língua estrangeira, compreendi um dos motivos que levam a gramática de uma língua estrangeira a ser abordada tradicionalmente: o professor não ser um agente de letramento. (Ana)

Aomobilizar-seem relaçãoao conceito deconstruçõesidentitárias e letramento como prática social (KLEIMAN e MATÊNCIO, 2005), Ana parece encontrar um caminho. Reposicionar-se como agente de letramento é o que seu texto sugere. Por sua vez, no texto de Maria emerge a questão de mudar algo na sala de aula, como pode ser visto abaixo:

\section{Fragmento (7)}

Um outro evento que registrei no diário concerne às minhas aulas. Tenho constantemente me feito os seguintes 
questionamentos: como estou dando minhas aulas? o que tenho feito para contribuir com a aprendizagem de meus alunos? Há interação entre conteúdo/alunos/professora? Tenho considerado as necessidades reais de meus alunos? Estes e outros questionamentos vêm sendo motivo de preocupação durante as preparações de minhas aulas bem como durante a execução dos conteúdos em sala. Não que essas preocupações não existissem antes, apenas elas passaram a ter um sentido diferente, creio que o olhar sobre minha prática docente esteja mudando... Como resultado deste 'novo olhar', é que ousei usar'uma certa adaptação' da estratégia do diário com uma turma de doze alunos no curso de Letras. (Maria)

No texto de Maria vemos que a professora retrata seus fazeres com os seguintes verbos: registrei, como estou dando, o que tenho feito, tenho considerado, ousei usar 'uma certa adaptação' da estratégia do diário... Escreve no diário, se questiona sobre sua prática e decide ousar. Enquanto que no texto de Ana constrói-se retratos do professormáquina e professor-diretor, com a professora-autora descrevendo o seu fazer e se posicionando neste contínuo, no texto de Maria vemos que seu fazer muda em função de um novo olhar - talvez primeiros passos na direção de um posicionamento de professor-pesquisador, a postura que é saliente ao longo de sua narrativa. No fragmento 2 acima, já sugere que gostaria de tentar me envolver num projeto dessa natureza, sendo que descreve e avalia uma atividade realizada com seus alunos, em função de sua própria vivência com o diário de aprendizagem na disciplina, como se vê a seguir:

\section{Fragmento (8)}

Como resposta à minha solicitação, os alunos fizeram uma descrição que variou desde uma exposição escrita superficial até as mais detalhadas. Todos apontaram pontos positivos em primeiro momento e depois colocaram as dificuldades enfrentadas que comprometeram em alguma etapa sua aprendizagem. Mas, não chegaram a fazer análise das questões. Após a correção do texto deles, devolvi-o com observações e comentários ou, em alguns casos, sugeri encontros individuais para esclarecer algumas dúvidas sobre o que eles escreveram, quando as idéias deles não estavam muito claras -- vale acrescentar que a atividade foi desenvolvida em inglês. Fiquei com um sentimento de incompletude, pois nem todos puderam comparecer ao encontro sugerido, ou me deram qualquer outro 'feedback'. (Maria) 
122 Reichmann - Professoras-em-construção: reflexōes sobre diários...

Narra o que fez em aula com sendo uma certa adaptação da estratégia do diário e prossegue avaliando sua atuação:

\section{Fragmento (9)}

Mesmo assim, achei que a atividade foi válida, apesar de achar algumas falhas de metodologia. Primeiro, acho que devia ter pedido pra eles fazerem anotações no diário ao longo da unidade estudada e não somente após o termino dela; segundo, devia ter comentado com todos os alunos coletivamente mịnha avaliação de suas colocações -- em vez de fazê-lo individualmente, e mesmo assim, apenas com alguns alunos; terceiro, percebi que a atividade foi bem aceita, apesar de alguns terem se colocado muito superficialmente; quarto, devia ter continuado com a estratégia do diário após o termino de cada conteúdo estudado ao longo do semestre. Isso me daria subsídios para uma análise mais precisa; e por fim, eu devia ter tirado cópias dos textos deles, para comparar com outros textos de futuros alunos sobre a mesma atividade, pois estou pensando em introduzir a prática do diário numa turma de Letras no próximo semestre, e desta vez penso em usá-lo ao longo do semestre, desde os primeiros encontros. (Maria)

No trecho acima, com seu novo olhar a professora avalia que a atividade foi válida - e segue com reconstruções, sinalizadas por devia ter pedido, devia ter continuado, daria subsídios para uma análise, devia ter tirado cópias, como também por indicações do que pretende fazer futuramente, tais como estou pensando em introduzir a prática do diário, penso em usá-lo ao longo do semestre. Essas reconstruções sugerem uma nova trilha a ser percorrida, a possibilidade de atuar como professora-pesquisadora.

Em suma, após este breve olhar sobre os textos das professoras Ana e Maria, mapeando alguns reposicionamentos potenciais que emergem nas suas narrativas, partiremos para algumas reflexões finais apontadas por essas histórias profissionais.

\section{Considerações finais}

Este artigo propõe uma releitura das paisagens de saberes profissionais construídas por duas professoras de língua inglesa engajadas na produção de diários reflexivos - e que posteriormente (re)escreveram suas percepções acerca do seu processo de 
aprendizagem como requisito final para a disciplina Fundamentos de Lingüística Aplicada. Através da escritura, as professoras retratam seus conflitos e tensões, buscam suas próprias razões para atuar e renovam-se profissionalmente. $\mathrm{Na}$ releitura particular proposta neste artigo, através de fragmentos selecionados onde o ator social retratado é o professor-em-ação, isto é, onde se vislumbra a atuação profissional das próprias professoras-autoras, verificouse que nos fragmentos da professora Ana é construída a figura do professor-máquina (com a qual não se identifica), e num lugar diametralmente oposto a esse é construída uma figura com a qual Ana se identifica mais, a de professor-diretor-de-peça-teatral, isto é, de professor como agente de letramento. No texto de Maria vemos emergir o posicionamento de professor-pesquisador. Concluímos que as reconstruções nos textos de Ana e Maria reiteram sutilmente esses reposicionamentos, sugerindo que o como fazer diferente pode significar um alinhar-se a ser diferente.

Abrindo um parêntese, em uma busca recente através da ferramenta de busca 'Google'(acesso em 26/02/2007), ao se clicar nas seguintes palavras-chave, apareceram os seguintes números de links', respectivamente: diário docente, 12; diários de aprendizagem, 58; narrativas docentes, 115; relatos reflexivos, 140; diários dialogados, 155; narrativas de aprendizagem, 326; diários reflexivos, 368; blogs docentes, 621 . Esses números têm crescido visivelmente; através da citada ferramenta de busca, a autora tem presenciado esta tendência crescente - sendo que os blogs docentes prometem ser um excelente campo de pesquisa (como também bancos de dados tais como o do projeto AMFALE, www.veramenezes.com, que agrega narrativas de aprendizagem). Enfim, o presente trabalho parece estar em sintonia com esta 'virada narrativa', pois é evidente o crescente engajamento em práticas alicerçadas em narrativas de aprendizagem

$\mathrm{Na}$ introdução foram apontados alguns desafios relativos à complexidade e pluralidade de variáveis envolvidas na formação de professores. Sublinhamos os desafios relativos à identidade profissional dos formadores (GIMENEZ, 2005) e à formação docente localizada (JOHNSON, 2006); como aponta Signorini (2006:204), é necessário pensarmos em "um modelo inclusivo crítico de formação...um modelo que visa ao empoderamento do professor e à sua afirmação profissional". Alinhando-se a esses desafios, nesse projeto de formação em curso podemos observar 
124 Reichmann - Professoras-em-construção: reflexōes sobre diários...

o impacto vital da produção diarista, "catalisando ações e atitudes consideradas mais produtivas para o processo de formação de professores" (ibid).

Em suma, este trabalho dá visibilidade às histórias de duas professoras e uma formadora, a qual entende que a reflexão-sobrea-ação como uma prática discursiva sistemática pode constituir uma etapa na direção de um reposicionamento identitário, como o de professor-pesquisador - iluminando a vida na sala de aula. E em pleno século XXI, já está mais do que na hora da recente virada sociocultural nas ciências humanas fazer-se presente na sala de aula de língua estrangeira em instituições públicas de ensino, facilitando o empoderamento docente e discente. A produção diarista pode ser um passo inicial de um caminho possível.

\section{Referências Bibliográficas}

BAILEY, K. The use of diary studies in teacher education programs. In: J.C.Richards e D. Nunan (orgs.). Second language teacher education. Cambridge: Cambridge University Press, p. 215-226, 1990.

BARTLETT, L. Teacher development through reflective teaching. In: J.C.Richards e D. Nunan (orgs.). Second language teacher education. Cambridge: Cambridge University Press, 202-214, 1990.

BURTON, J.The Importance of teachers writing on TESOL. TESL-EJ, v.9, $\mathrm{n}^{\circ}$ 2, p.1-18, 2005.

BURTON, J. e CARROLL, M. (orgs.). Journal writing. Alexandria, VI: TESOL Inc, 2001.

BURTON, J., QUIRKE, P. e REICHMANN, C.L. (orgs). Reflective writing - a way to lifelong teacher learning. NY: Cambridge University Press. (em preparação).

CELANI, M.A.A e MAGALHÃES, M.C.C. Representações de professores de inglês como língua estrangeira sobre suas identidades profissionais. In: L.P.M.Lopes e L.C.Bastos (orgs.). Identidades: recortes multi $e$ interdisciplinares. SP: Mercado de Letras, p.319-338. 2002.

CONNELLY, F.M. e CLANDININ, D.J. Shaping a professional identity: stories of educational practice. NY: Teachers College Press, 1999.

DUBAR, C. Para uma teoria sociológica da identidade. In: A socialização: construção de identidades sociais e profissionais. SP: Livraria Martins Fontes Editora, p.133-156, 2005. 
ELBAZ, F. Research on teacher's knowledge: the evolution of a discourse. Journal of Curriculum Studies 23, (1), 1-19, 1991.

Critical reflection on teaching: insights from Freire. In: Journal of Education for Teaching, 14 (2), 171-181, 1988.

FAIRCLOUGH, N. Discourse and social change. Cambridge: Polity Press, 1992.

FREEMAN, D. (1996). Redefining the relationship between research and what teachers know. In: K. Bailey e D. Nunan (orgs). Voices from the language classroom. Cambridge: Cambridge University Press, 88-115, 1996.

Teacher training, development and decision making: a model of teaching and related strategies for language teacher education. TESOL Quarterly, 23, 27-45, 1989.

FREIRE, P. Pedagogy of the oppressed. New York: Seabury Press, 1970.

GIMENEZ, T. Desafios contemporâneos na formação de professores de línguas: contribuições da Lingüística Aplicada. In: FREIRE,M.M., ABRAHÃO,M.H.V. e BARCELOS, A.M.F.(orgs.). Lingüística Aplicada e Contemporaneidade. São Paulo, SP: ALAB, Campinas, SP: Pontes Editores, p.183-201, 2005.

HALLIDAY, M.A.K. An introduction to functional grammar. London: Edward Arnold, 1994.

HASAN, R. Part B. In: M.A.K. Halliday and R. Hasan (orgs). Language, context, and text: aspects of language in a social semiotic perspective. Oxford: Oxford University Press, 52-118, 1989.

JOHNSON, K. The sociocultural turn and its challenges for second language teacher education. TESOL Quarterly, vol.40, no.1, março de 2006.

JOHNSON, K. e GOLOMBEK, P. (orgs). Teacher narratives as professional development. Cambridge: Cambridge University Press, 2002.

KEMMIS, S. e McTAGGART, R. The action research planner ( $3^{\text {rd }}$ ed.). Geelong, Australia: Deakin University Press, 1988.

KLEIMAN, A e MATÊNCIO, M.L.M.(orgs.). Letramento e formação de professores: práticas discursivas, representações e construção do saber. SP: Mercado de Letras, 2005.

LAVE, J. e WENGER, E. Situated learning: legitimate peripheral participation. Cambridge: Cambridge University Press, 1991.

LIBERALI F. O diário como ferramenta crítica. Tese de doutorado inédita. PUC-SP, 1999. 
126 Reichmann - Professoras-em-construção: reflexōes sobre diários...

LUDKE, M. O professor, seu saber e sua pesquisa. Educação e Sociedade, ano XXII, $\mathrm{n}^{\circ} 74,2001$.

McDONOUGH, J. e McDONOUGH, S. Research methods for English language teachers. London: Arnold, 1997.

MELLO, D.M. de. Histórias de subversão do currículo, conflitos e resistências: buscando espaço para a formação docente na aula de língua inglesa do curso de Letras. Tese de doutorado inédita, PUC-SP, 2005.

MOITA LOPES, L.P. Contemporaneidade e construção de conhecimento na área de estudos lingüísticos. SCRIPTA, Belo Horizonte, v.7, ํㅜㄹ p. 159$171,1^{\circ}$ semestre 2004 .

Oficina de Lingüística Aplicada. SP: Mercado de Letras, 1996.

REICHMANN, C.L. Reflection as social practice: an in-depth linguistic study of teacher discourse in a dialogue journal. Tese de doutorado inédita. PGI, UFSC, 2001.

Beyond the eye: video analysis in language learning. Tese de mestrado inédita, School for International Training, 1992.

ROMERO, T. R. S. A interação coordenador e professor: um processo colaborativo? Tese de doutorado inédita, PUC-SP, 1998.

SCHÖN, D. The reflective practitioner: how professionals think in action. NewYork: Basic Books, 1983.

Educating the reflective practitioner. San Francisco: Josey-Bass, 1987.

SIGNORINI, I. (org). Gêneros catalisadores: letramento e formação do professor. SP: Parábola Editorial, 2006.

SMYTH, J. Teachers' work and the politics of reflection. American Educational Research Journal, 29, (2), 1992.

VYGOTSKY, L. Mind in society: the development of higher psychological processes. Orgs.: M.Cole, V.John-Steiner, S. Scribner e E. Souberman. Cambridge: Harvard University Press, 1978.

ZEICHNER, K.M. Critical pedagogy and teacher education. Journal of Education, 169, (3), 1987. 